\title{
A Novel Method of Collecting and Chemically Characterizing Milligram Quantities of Indoor Airborne Particulate Matter
}

\author{
Gavin J. Parker' ${ }^{1}$, Chun H. Ong ${ }^{2}$, Robert B. Manges ${ }^{3}$, Emma M. Stapleton ${ }^{3}$, \\ Alejandro P. Comellas ${ }^{3}$, Thomas M. Peters ${ }^{2 *}$, Elizabeth A. Stone ${ }^{1^{*}}$ \\ ${ }^{1}$ Department of Chemistry, University of Iowa, Iowa City, IA 52242, USA \\ ${ }^{2}$ Occupational and Environmental Health, University of Iowa, Iowa City, IA 52242, USA \\ ${ }^{3}$ Department of Internal Medicine, Roy J. and Lucille A. Carver College of Medicine, University of Iowa, Iowa City, IA \\ 52242, USA
}

\begin{abstract}
Because people spend the majority of the day indoors, it is important to evaluate indoor air, especially airborne particulate matter (PM), for its potential health effects. However, collecting milligram-sized samples of indoor PM, which are necessary for detailed chemical and biological assays, remains challenging because of the noise, power requirements, and size of traditional PM samplers. Therefore, we developed a novel method of collection using an electrostatic precipitator (ESP). Laboratory experiments were conducted to characterize the ESP collection efficiency (41-65\%) and PM recovery (50-95\%) for three aerosol types. After characterization, the ESPs were deployed in 21 homes in eastern Iowa for 30 days, during which they collected 6-87 mg of indoor PM. The samples were acid digested and subsequently analyzed by inductively coupled plasma mass spectrometry for their magnesium, aluminum, vanadium, manganese, iron, nickel, copper, zinc, arsenic, and lead content. Crustal metals (magnesium, iron, and aluminum), ranging from 3,000 to $25,000 \mathrm{ng} \mathrm{mg}^{-1}$ in concentration, contributed the largest mass fractions of the PM. The relative abundances of the metals were similar between homes, although the PM mass fractions were highly variable. This ESP sampling method can be applied in future studies to collect milligram-sized quantities of indoor PM, enabling a detailed analysis of its composition and potential health effects.
\end{abstract}

Keywords: Indoor air; Particulate matter; Electrostatic precipitation; Metals.

\section{INTRODUCTION}

The adverse health effects of exposure to ambient particulate matter (PM) depend on its chemical composition and physical characteristics (Kim et al., 2015). Essential elements like iron can support the growth of bacteria in the lung, contributing to bacterial respiratory infections due to reduced antimicrobial function that hinder airway innate immunity (Bullen et al., 2005; Ghio, 2009). Metals such as nickel, lead, and copper cause inflammatory stress, while vanadium and manganese are toxic and have adverse effects on the cardiovascular system (Duvall et al., 2008; Antonini et al., 2010; Cortijo et al., 2010). Indoor PM is particularly important to study because humans spend the majority of their time indoors; Americans, for example, spend an average of $80 \%$ of their time indoors (Wallace, 2012). Indoor PM has

\footnotetext{
${ }^{*}$ Corresponding author.

Tel.: (+1)-319-384-1863; Fax: (+1)-319-335-1270

E-mail address: betsy-stone@uiowa.edu (E.A. Stone);

thomas-m-peters@uiowa.edu (T.M. Peters)
}

been attributed to a multitude of sources, including cooking, home heating, deterioration of building furnishings, and particles entrained from outdoors (Jones, 1999; Zhao et al., 2006; Cortez-Lugo et al., 2008; Nazaroff, 2018). However, evaluating the chemical, physical, and biological properties of PM that can affect human health generally requires at least $4 \mathrm{mg}$ of material (McGee et al., 2003). Finding a means of affordable, inconspicuous collection of milligram-scale quantities of indoor PM is the focus of this study.

To collect and analyze suspended indoor PM, filter-based samplers or exposure monitors are typically used, because they provide particle collection with high efficiency and can accommodate large air flows, enabling collection of large sample masses (Kamens et al., 1991; Chow and Watson, 1998; Yanosky et al., 2002; Kalogerakis et al., 2005). However, strong air pumps are needed to overcome the pressure drops across filters, making these samplers noisy and requiring large amounts of electricity. The use of smaller pumps reduces noise and electricity consumption but decreases airflow rates and collects smaller quantities of PM (typically less than $1 \mathrm{mg}$ ). Vacuum cleaner methods have been used to collect settled dust with particle size resolution, but vacuums are particularly noisy and settled dust may not best represent 
inhalable particles (Cox et al., 2017).

An attractive option is the use of electrostatic precipitators (ESPs), which have been used in industry as large-scale air purification devices. Power plants use ESPs as pollution control devices to reduce particle emissions (Qi and Yuan, 2011). Due to their effectiveness at collecting aerosols, ESPs have been adapted for airborne particle sampling. The success in PM collection has prompted the National Institute for Occupational Safety and Health (NIOSH) to develop a handheld ESP to collect PM onto substrates for microscopy (Miller et al., 2010). Sample collection times in this application are very short ( $\sim 1$ minute) to avoid overloading of the substrate (Miller et al., 2010). ESPs used for aerosol sampling in current literature do not use its high-flow sampling capabilities, and thus do not collect large quantities of PM. Since ESP devices adapted for indoor PM sampling produce little noise, longterm sampling (30 days per the manufacturer's recommended length of use for optimal particle collection) can be achieved in a non-invasive way (Bacchiega et al., 2006).

The aims of this study are to 1) develop a method of collecting milligram quantities of indoor PM using an ESP that is not disruptive to the indoor environment, 2) deploy such ESPs for collection of indoor PM in a cohort study, and 3) evaluate the metal content of the collected PM. Our overarching goal is to collect sufficiently large samples of indoor PM to enable characterization by chemical and biological assays, and thereby better understand the role of indoor PM exposures on respiratory health.

\section{MATERIALS AND METHODS}

\section{Collection of indoor PM via Electrostatic Precipitation}

The O-Ion B-1000 ESP was selected from 4 ESPs (Table S1) as a means of collecting the total suspended particulate (TSP) because of the simplicity of harvesting PM from the collection electrode. The O-Ion B-1000 is also inexpensive, small $(0.43 \mathrm{~m} \times 0.14 \mathrm{~m} \times 0.17 \mathrm{~m})$, and portable, making it easily deployable in environments with limited space. The interior portion of this ESP is shown schematically in Fig. 1. The collection electrode is an elongated rectangle with concave sides. A wire electrode is held $7 \mathrm{~mm}$ from the center of the face of the collection electrode. Air is pulled through the unit with a squirrel cage blower located in the top of the ESP. It passes through slots in the lower portion of the outside of the housing, through the area with the wires and collection electrode, and finally through a small gap at the top of the ESP.

The carbon filter and the UV light at the exit of the commercial device were removed prior to sampling. For low and high settings on the ESP, the velocity of the air was measured with a thermal anemometer (VelociCalc 8360; TSI Inc., Shoreview, MN, USA) in 6 equally spaced locations in the plane of the ESP outlet. Airflow rate was calculated as the mean air velocity multiplied by the outlet area (low setting $=128 \mathrm{~L} \mathrm{~min}^{-1}$; high setting $=170 \mathrm{~L} \mathrm{~min}^{-1}$ ). At 0,5 , and $10 \mathrm{~cm}$ from the outlet of the ESP, ozone concentration was measured with an ozone sensor (PortaSens II portable gas leak detector; Analytical Technology Inc., Collegeville, PA, USA) and noise was measured at the outlet with a sound level meter (SoundTrack LxT; Larson Davis, Depew, NY, USA), each in triplicate.

\section{Determination of Particle Collection Efficiency}

The O-Ion B-1000 collection efficiency was characterized as a function of particle size for three polydisperse aerosols: sodium chloride $(\mathrm{NaCl})$, Arizona road dust (ARD), and diesel fumes. $\mathrm{NaCl}$ was selected as a common inorganic salt that has high water solubility (Sandu et al., 2010). $\mathrm{NaCl}$ aerosol was generated at fine and ultrafine particle sizes $(<1 \mu \mathrm{m}$ ) by spraying $0.9 \% \mathrm{NaCl}$ irrigation solution (2F7123; Baxter Healthcare Co., Deerfield, IL) with a vibrating mesh nebulizer (Aeroneb Solo System; Aerogen, Ireland) followed by drying with a silica dryer. Diesel fumes were chosen to represent combustion particles that have low water solubility (Figler et al., 1996). The diesel fume particles were generated at fine and ultrafine particle sizes by a diesel generator (DG6LE; Red Hawk Equipment, LLC, Akron, NY, USA). ARD consisted primarily of coarse particles $(>1 \mu \mathrm{m})$ and was selected to represent a crustal dust that may enter homes through resuspension of soil tracked in from outdoors or from intrusion of windblown dust (Curtis et al., 2008). A fluidized bed aerosol generator (Model 3400A; TSI Inc.,

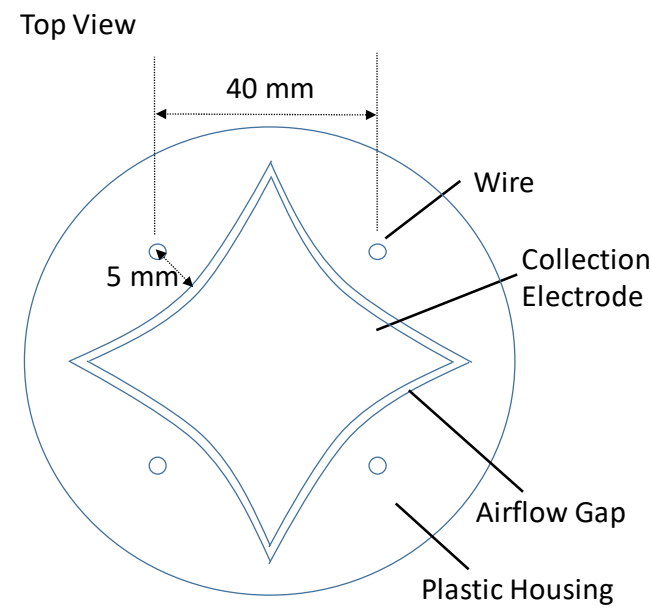

Side View

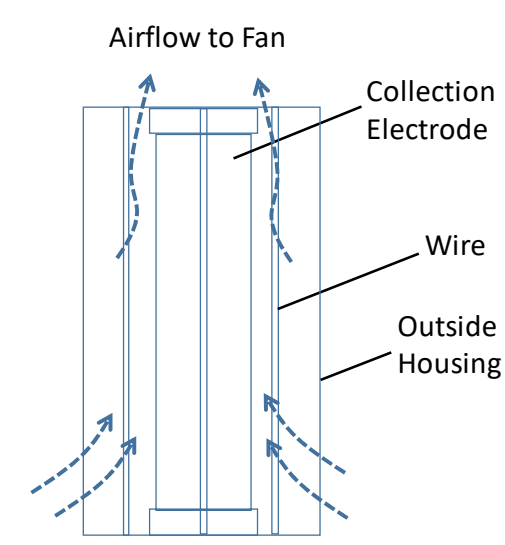

Fig. 1. Schematic diagram of the electrostatic precipitator portion of the O-Ion B-1000. 
Shoreview, MN, USA) was used to aerosolize ARD (Fine Grade, Part No. 1543094.; Powder Technology, Inc., Arden Hills, MN, USA). Together, these three aerosol types span a broad range of aerosol sizes, chemical composition, and degree of water solubility.

Collection efficiency was determined experimentally (Fig. 2). Aerosols were injected into the mixing chamber $(0.64 \mathrm{~m} \times 0.64 \mathrm{~m} \times 0.66 \mathrm{~m})$ and diluted with clean air that had been passed through two high-efficiency particulate air filters. A condensation particle counter (CPC) (Model 3007; TSI Inc., Shoreview, MN, USA) was used to monitor the particle concentration in the chamber. Size-resolved aerosol number concentrations were measured with a scanning mobility particle sizer (SMPS; composed of an Electrostatic Classifier Model 3082 and a Nano Water-Based Condensation Particle Counter Model 3788; TSI Inc., Shoreview, MN, USA) for particles smaller than $1 \mu \mathrm{m}$ and an Aerodynamic Particle Sizer (APS; Model 3321; TSI Inc., Shoreview, MN, USA) for particles larger than $1 \mu \mathrm{m}$. Size-resolved aerosol number concentrations were measured upstream of the ESP with the electric field off, downstream of the ESP with the electric field off, and downstream of the ESP with the electric field on.

Collection efficiency was calculated from the number concentration downstream of the ESP with electric field turned off $\left(\mathrm{C}_{\text {down, off }}\right)$ and turned on $\left(\mathrm{C}_{\text {down, on }}\right)$ following Eq. (1):

Collection Efficiency $=1-\frac{C_{\text {down }, o n}}{C_{d o w n, o f f}}$

\section{Recovery of PM from the ESP Electrode}

PM was collected from the ESP electrode using a filter wiping method described by Afshar-Mohajer et al. (2017) in which polyvinyl chloride (PVC) filters wetted with isopropanol were used to wipe PM from an ESP collection electrode (Afshar-Mohajer et al., 2017). Because isopropanol oxidizes the surface of the electrode (O-Ion Technologies, 2016) and reduces its collection efficiency, isopropanol was replaced with deionized (DI) water in this study. Filters were pre- and post-weighed using a microbalance (MT-5; Mettler-Toledo, Columbus, $\mathrm{OH}, \mathrm{USA})$ in a temperature $\left(21-24^{\circ} \mathrm{C}\right)$ and humidity $(40-41 \% \mathrm{RH})$ controlled room to determine the mass of PM collected from the ESP.

Filters wetted with $1 \mathrm{~mL}$ of DI water were used to wipe the electrode in an up-and-down motion for a total of four cycles on each of the four sides or until no observable PM remained. A minimum of two filters were used on each side of the electrode. After drying for 48 hours, filters were reweighed. Eight laboratory blanks were collected (four before deployment, four after deployment) by wiping a clean ESP.

The efficiency of particle recovery from the electrode was determined in the laboratory experiments described in Section 2.1 b, each in triplicate. Particles were collected onto a pre-cleaned ESP electrode for 30 minutes, while PM mass was simultaneously collected on $37 \mathrm{~mm}$ PVC filters (FPVC537; Zefon International, Inc., Ocala, FL, USA) in a cassette sampler operating at an airflow of $10 \mathrm{~L} \mathrm{~min}^{-1}$ (Gilian 12; Sensidyne, LP, St. Petersburg, FL, USA). PM from the ESP electrode was collected by the wetted filter method. Particle recovery $(\mathrm{R})$ was calculated as the ratio of the mass of PM recovered from the ESP electrode $\left(\mathrm{m}_{\mathrm{ESP}}\right)$ and the expected PM mass measured in the chamber following Eq. (2):

$$
R=\frac{m_{E S P} \times Q_{37}}{Q_{E S P} \times m_{37} \times C E_{E S P}}
$$

where $m_{37}$ is the mass collected from the chamber on a $37 \mathrm{~mm}$ PVC filter, $\mathrm{Q}_{37}$ is the flow rate for the cassette sampler, $\mathrm{Q}_{\mathrm{ESP}}$ is the flow rate of the ESP device, and CEESP is the collection efficiency of the ESP device. The collection efficiency of the cassette sampler is assumed to be 1 .

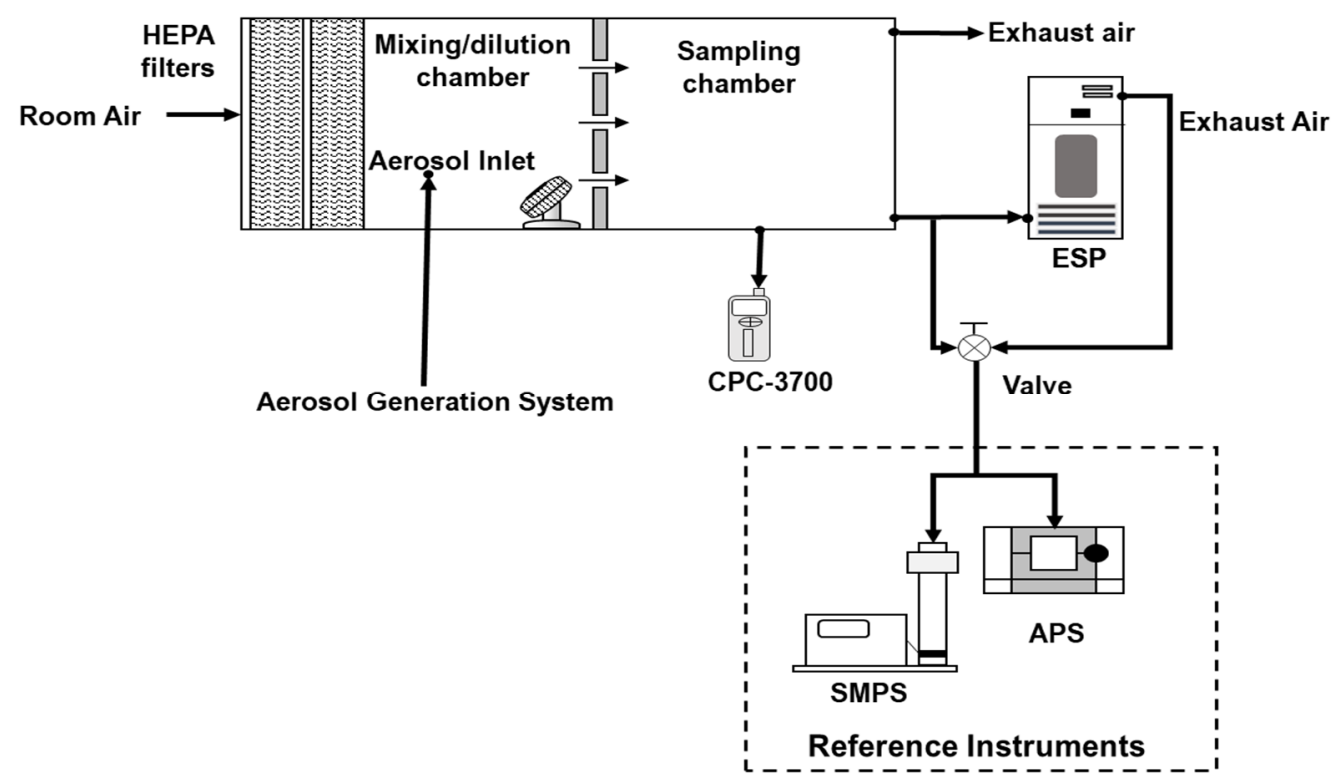

Fig. 2. Experimental setup used to measure collection efficiency by particle size. Each aerosol generation system was designed for the specific aerosol type: Sodium chloride, Arizona road dust, or diesel fumes. 


\section{Field Deployment}

ESPs were deployed in the homes of 21 former and current smokers with and without chronic obstructive pulmonary disease (COPD) for 30 days. The ESP collection device was transferred to patients at a clinic visit during which they received training on its installation and operation. Surveys were used to collect data from study participants about frequency and methods of cleaning and cooking, cigarette smoking, candle use, home heating methods, pets, home renovation projects, and square footage of the home. Patients installed the device in their home in the room where they spend the most time, generally in the living room or bedroom. Patients then returned the ESP to the clinic after the 30-day collection period. Recovery of collected material required eight filters, except in the case of one heavily loaded ESP that required nine. Two filters were used on each of the four sides of each collection electrode. The amount of PM collected during the field sampling was measured gravimetrically. PM mass measurements were not corrected for particle collection efficiency or recovery from the electrode.

\section{Sample Digestion and Analysis of Metals}

To evaluate metals in indoor PM, PM samples recovered from the ESPs were digested in acid and analyzed by inductively coupled plasma mass spectrometry (ICP-MS). Filters were placed in a modified polytetrafluoroethylene (PTFE-TFM) vessel with $6 \mathrm{~mL}$ of concentrated nitric acid (68-70\% w/w Fisher), $1 \mathrm{~mL}$ of hydrogen peroxide $(30 \% \mathrm{w} / \mathrm{w}$ Sigma-Aldrich), and a $50 \mu \mathrm{g} \mathrm{L}^{-1}$ indium (Perkin Elmer) internal standard spike. Once submerged in the acid matrix, the filters were digested with microwave assistance (Multiwave GO; Anton Paar). The microwave program began with a 30-minute ramp to $200^{\circ} \mathrm{C}$ followed by a 30 -minute hold, following a modified version of EPA Method 3051 that provides greater recoveries of metal analytes (Hewitt and Cragin, 1991; Hassan et al., 2006). A 50\% v/v nitric acid solution was used to quantitatively transfer solutions, and a $2 \%$ nitric acid solution was used to reconstitute samples to $10 \mathrm{~mL}$. A 1:10 dilution in $2 \%$ nitric acid was performed prior to instrumental analysis. The accuracy and precision of the extraction method were determined using a standard reference material (SRM) of indoor PM (NIST 2584, trace elements in indoor dust).

Metals were analyzed using an ICP-MS (7900 ICP-MS; Agilent) equipped with a collision cell to reduce interference from other ions in the solution. An 11-point calibration curve was prepared from a multi-element standard (QCPQCS-3; Inorganic Ventures) spanning 0.1-500 $\mu \mathrm{g} \mathrm{L}^{-1}$, with an indium internal standard concentration of $50 \mu \mathrm{g} \mathrm{L}^{-1}$. Analyte masses and the order of samples for analysis followed National Environmental Methods Index (NEMI) Standard Method 3125 to account for memory effects, interferences, and matrix effects (NEMI, 2018). Before each batch of sample analysis, the instrument was stabilized and tuned to achieve $<10 \%$ RSD for all analytes of interest.

Accuracy and precision of digestion methods were evaluated using spike recovery experiments. Reference material (NIST 2584, trace elements in indoor dust) was spiked onto three blank PVC filters and digested alongside three blank PVC filters. Spike recoveries were calculated using Eq. (3).
Recovery $\%=\frac{\left(C_{\text {recovered }}-C_{\text {blank }}\right)}{C_{\text {spiked }}} \times 100$

\section{RESULTS AND DISCUSSION}

\section{Characterization of ESP Performance}

From the four ESPs considered for the collection of indoor PM (Table S1), the O-Ion B-1000 was selected because of its small size, low cost, removable carbon filter and UV-C light, quiet fans, and easily removable collection electrode. The noise level generated by the ESP on the high setting was $45.8 \pm 0.2 \mathrm{~dB}$ and on the low setting was $43.1 \pm$ $0.4 \mathrm{~dB}$ (Table S2), comparable to a small box fan. The noise levels were near the EPA suggested indoor-environment noise levels $(\sim 45 \mathrm{~dB})$ that permit spoken conversation and allow for sleeping and recreational activities (Fink, 2017). The noise levels were well below the $70 \mathrm{~dB}$ limit that when exceeded over 24 hours, is likely to produce measurable hearing loss over a lifetime.

A problem with using an ESP for sampling is that any use of electrostatics will produce ozone, a chemical species known to cause airway inflammation, from surrounding oxygen in the air (Cardello et al., 2002; Lippmann, 2012). It was thus important to determine whether the O-Ion B-1000 would generate harmful levels of ozone. Ozone production on the low setting of the ESP device was $0.04 \mathrm{ppm}$ at the outlet, $0.04 \mathrm{ppm} 5 \mathrm{~cm}$ from the outlet, and nil at $10 \mathrm{~cm}$, meaning at all distances ozone concentration was below the EPA standard of $0.07 \mathrm{ppm}$ (Table S3). When switched to the high setting, $0.12 \mathrm{ppm}$ ozone was produced at the outlet, $0.088 \mathrm{ppm} 5 \mathrm{~cm}$ away, and reduced to $0.047 \mathrm{ppm} 10 \mathrm{~cm}$ from the outlet (Table S3). The greater airflow rates on the higher ESP setting resulted in three times the amount of ozone produced at the outlet and twice as much ozone produced 5 $\mathrm{cm}$ from the outlet. The removal of the carbon filter provided with the O-Ion B-1000 slightly increased the amount of ozone produced, though each setting and distance produced ozone concentrations within $0.01 \mathrm{ppm}$ of that measured with the carbon filter (Table S4). Since flow rate has been shown to be important with ozone production, removal of the carbon filter likely provides a small increase in flow rate that subsequently increased ozone concentration. The limit of ozone exposure set from National Ambient Air Quality Standards (NAAQS) is $0.070 \mathrm{ppm}$ over 8 hours, and exceedance of this concentration can cause various health effects: coughing, deep pain in the respiratory tract, shortness of breath, and increased susceptibility to lung disease (U.S. PEA, 1982; Lippmann, 2012). With sufficient and typical household ventilation, the ESP will not generate enough ozone to exceed the NAAQS limit and should not be a problem in field deployment of the device.

\section{Collection Efficiency of the ESP}

The collection efficiency of the ESP was characterized by using three aerosol types, including a soluble salt, combustion particles, and airborne crustal matter, thereby encompassing a range of chemical species likely to be present in the indoor environment (Fig. 3). From 40-400 nm, collection 
efficiencies of $\mathrm{NaCl}$, diesel, and $\mathrm{ARD}$ were similar at $45 \%$. This finding is consistent with typical ESP efficiencies, where the efficiency is commonly lowest between about $0.1 \mu \mathrm{m}$ and $1 \mu \mathrm{m}$ (Mizuno, 2000). Neither diffusion charging (random collisions that induce charge) nor field charging (ions travel along electric field lines and intersect with particles) dominate for particles in this size range. Consequently, the system produces fewer charged particles and collection efficiency is reduced (Hinds, 1999; Hinds, 2004; Miller et al., 2010). For particles larger than $400 \mathrm{~nm}$, the efficiency of the ARD increased with particle size as field charging became the predominant charging mechanism. With field charging, increasingly large particles achieve greater electrical mobility toward the electrode (Hinds, 2004).

For particles smaller than $100 \mathrm{~nm}$, the predominant mode of particle deposition is diffusion charging (Miller et al., 2010). With diffusion charging, the migration velocity in an ESP is proportional to the Cunningham correction factor, a correction to predict drag force for smaller particles (Mizuno, 2000). The collection efficiency for $\mathrm{NaCl}$ particles smaller than $40 \mathrm{~nm}$ increased with decreasing particle size, due to diffusion charging being the predominant mode of particle charging resulting in migration to the collection electrode.
The difference in efficiency for $\mathrm{ARD}$ and $\mathrm{NaCl}$ particles larger than $400 \mathrm{~nm}$ may be due to $\mathrm{NaCl}$ having a higher electrical resistivity than $\mathrm{ARD}$, although their respective electrical resistivities are not known. The higher resistivity would make it more difficult to collect particles, resulting in a lower collection efficiency.

Over the full range of particle sizes generated, the average collection efficiencies were $43 \%$ for $\mathrm{NaCl}, 41 \%$ for diesel fumes, and 59\% for ARD (Table S5). Collection efficiencies in this range are typical for an ESP and suggest a slight preference for the collection of large particles $(>400 \mathrm{~nm})$ by field charging over small particles $(<100 \mathrm{~nm})$ by diffusion charging.

\section{PM Recovery}

Particle recovery from the collection electrode was evaluated for the three aerosol types. Wetting the PVC filter with DI water resulted in a $21 \%$ increase of ARD recovered from the collection electrode compared to wiping with a dry PVC filter (Table S6). In order to remove all visible PM from one collection electrode, three wet filters or four dry filters were required. The first filter used to clean each side of the electrode generally had a higher mass, with subsequent filters collecting less material.

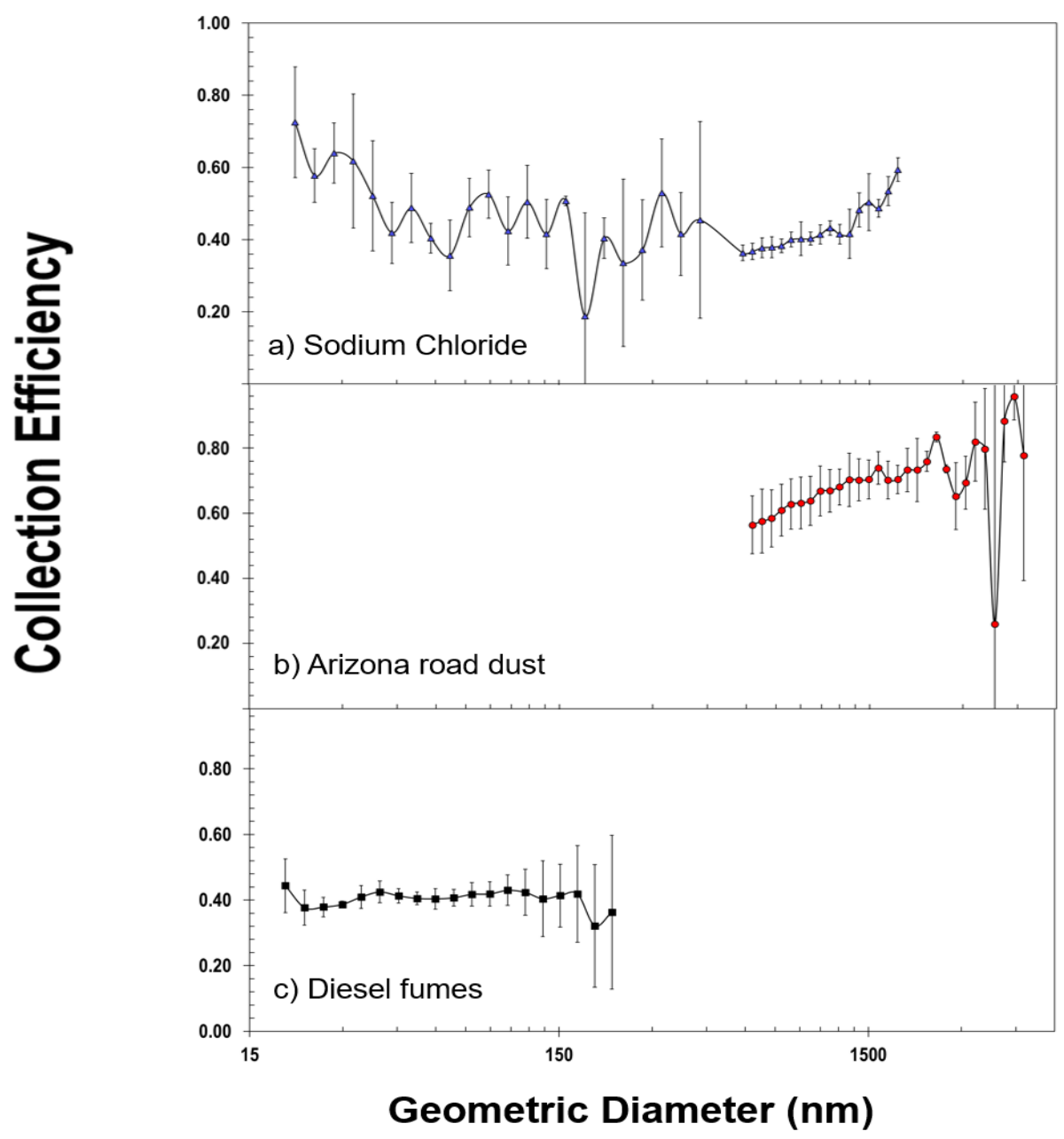

Fig. 3. Collection efficiency of ESP for $\mathrm{ARD}, \mathrm{NaCl}$, and diesel fumes in relation to particle geometric diameter. Error bars correspond to one standard deviation. 
Using this method, $\mathrm{NaCl}$ had the greatest recovery of 95 $\pm 5.8 \%$, followed by ARD at $63 \pm 1.9 \%$, and then diesel fumes at $48 \pm 11.2 \%$ (Table S5). The high recovery of $\mathrm{NaCl}$ is attributed to its high water solubility, which made it easier to remove the particles from the collection electrode. ARD is partially water-soluble, making the particles easier to remove. ARD is also composed of primarily large particles, which can be easily dislodged from a surface. Thus, the lower than anticipated particle recovery for ARD may be attributed to particles falling off the electrode during the filter wipe process. ARD was also the most consistent recovery, with a standard deviation of $1.9 \%$. The lower recovery of diesel PM is likely attributable to diesel fumes being insoluble in water, which made it difficult to recover as the particles became viscous. Overall, the recovery data suggest that wiping the electrode with filters wetted with water preferentially recovers water-soluble species and is less effective at removing low-solubility combustion particles.

\section{Limitations of the ESP Collection Method for Indoor PM}

While capable of collecting milligram quantities of airborne PM indoors, there are notable limitations of the ESP method. There is a preference towards the collection of coarse particles $(2.5-10 \mu \mathrm{m})$ like crustal materials relative to smaller, potentially more toxic, fine particles $(<2.5 \mu \mathrm{m})$ that arise from combustion. Meanwhile, the collection efficiency for particles $>10 \mu \mathrm{m}$ is not known because it was not accessible by the particle measurement devices used for ESP characterization. Because there is no particle sizing upstream of the collection electrode, TSP is collected. Consequently, there is potential for a small number of large particles to have a substantial impact on the measured particle mass. Also, there is the preference towards the collection of recovery of water-soluble species from the electrode surface relative to low-solubility combustion particles, resulting in chemical differences in the collected PM relative to the recovered PM. The characterization studies conducted herein provide some bounds on the extent to which collection efficiency and particle recovery vary across different particle sizes and types.

\section{Field Results}

The average mass of indoor PM collected was $20.8 \mathrm{mg}$ with a standard deviation of $17.3 \mathrm{mg}$, a range of $6.36-86.7 \mathrm{mg}$, and propagated error ranging from $0.008-0.013 \mathrm{mg}$ (Fig. 4). There was no significant relationship between the square footage of the home and the mass of dust collected $(r=-0.27$, $\mathrm{p}=0.30$ ). High PM masses generally corresponded to homes in which tobacco is smoked and with a high frequency of vacuuming, although the significance of these trends could not be established due to the low sample numbers in this study. The variability in PM collected is attributed to indoor PM loadings that vary with building furnishings, airflow pathways, ventilation, number of occupants, number of pets, frequency of cleaning, open or shut windows, and household activities such as cleaning or combustion processes (cooking, heating, smoking, candle burning, etc.).

\section{Determination of Metals in Indoor PM}

Three methods of digesting PVC filters for analysis of

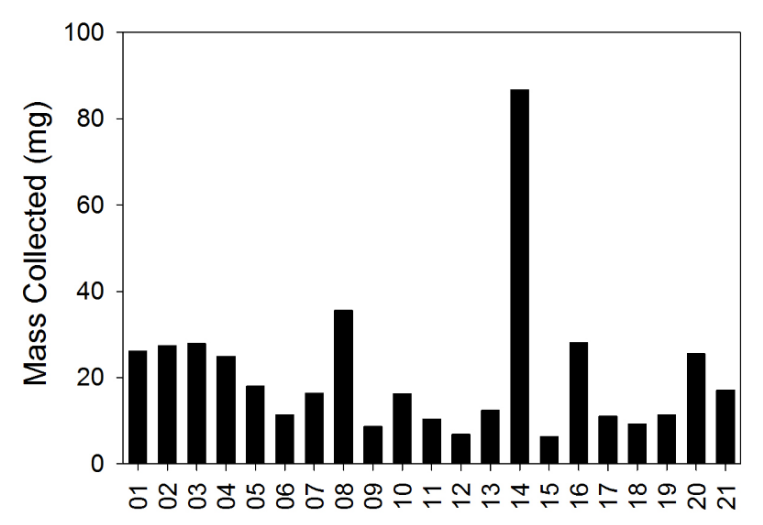

ESP ID

Fig. 4. Mass of indoor PM wiped from ESPs deployed in homes for 30 days over winter and measured using a Mettler Toledo MT-5 microbalance.

total metals were examined, including use of hot plates with two acid matrices and microwave-assisted digestion (Fig. S1). Hot plate digestion with an acid matrix of $5 \mathrm{~mL}$ concentrated nitric acid $(68-70 \% \mathrm{w} / \mathrm{w})$ and $1 \mathrm{~mL}$ concentrated hydrofluoric acid $(49 \% \mathrm{w} / \mathrm{w})$ yielded recoveries ranging $16-93 \%$. Recoveries were improved to $82-98 \%$ (except for arsenic at $8 \%$ when hydrogen peroxide was added to aid in the oxidation of organic material and more complete digestion of the sample (Mesko et al., 2011). With microwave digestion, recoveries ranged from $80-98 \%$. The microwave-assisted method generally provided more accurate and precise (RSD $=6.9 \%$ ) spike recoveries (Fig. S2) and a much shorter digestion time (2 hours as opposed to 72 hours with a hot plate). Overall, the microwave digestion system was preferred for its efficiency, consistency, and capability to digest material without the use of hydrofluoric acid.

Metals were analyzed in the indoor PM collected from 21 homes of smoker subjects with and without COPD. Two of the eight PVC filters were digested from each household, along with eight field blanks. Weighted average mass concentrations were calculated to account for the differences in PM loadings across filters (Table S7). The most abundant metals observed were magnesium, aluminum, and iron; these metals were almost an entire order of magnitude more concentrated than were the other species (Fig. 5). This trend was also observed in prior studies (Rasmussen et al., 2001) and attributed to these being crustal metals commonly found in soil that can penetrate the indoor environment via windblown dust or adhering to materials entering the home (Curtis et al., 2008). Zinc, manganese, lead, and copper were also detected in each household sample at lower mass fractions. Zinc and copper are frequently found in building furnishings, and in cooking tools (See and Balasubramanian, 2008), while arsenic is associated with pesticides, but likely has additional sources. The mass fractions of metals in indoor PM were highly variable across homes, though their relative abundances were similar (Fig. 5).

The NIST 2584 SRM can be used to compare the metal mass fraction values of these studies' findings to a wellcharacterized sample of collected indoor PM. In the case of 


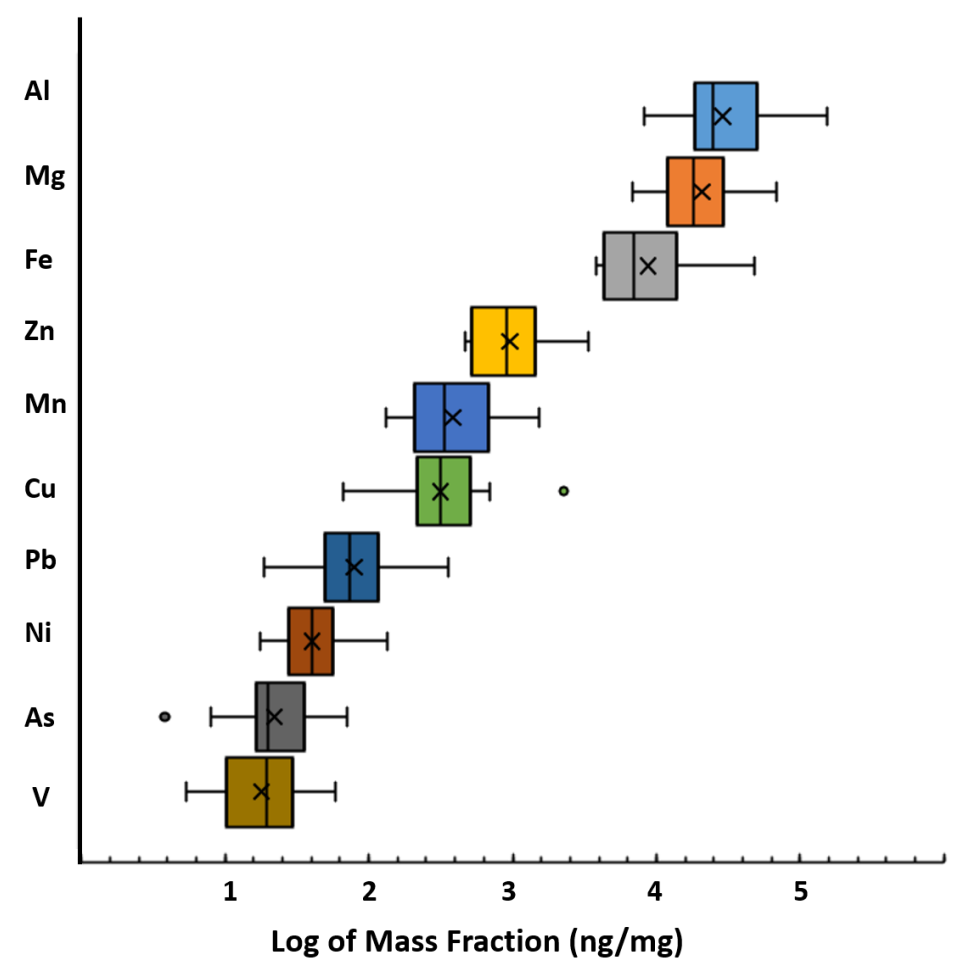

Fig. 5. Base $10 \mathrm{log}$ scale of metal mass fractions $\left(\mathrm{ng} \mathrm{mg}^{-1}\right)$ from 21 homes in eastern Iowa. The whiskers represent the minimum and maximum values for each species. The box is split into two pieces for the top and bottom half of the data with the median represented as a line in the middle. The average is shown with an "x."

lead the 21 households in eastern Iowa averaged $91.2 \mathrm{ng} \mathrm{mg}^{-1}$ while the NIST reference material had a lead concentration of $9761 \mathrm{ng} \mathrm{mg}^{-1}$. (In this study, none of the homes had leadbased paint, while all of those used to collect the NIST reference material did.) While the most abundant metals observed in this study were $\mathrm{Al}>\mathrm{Mg}>\mathrm{Fe}$, they were $\mathrm{Al}>$ $\mathrm{Fe}>\mathrm{Mg}$ in the NIST reference standard; this difference is likely due to variations in crustal composition from different geological locations. Nickel and zinc, for instance, have much lower abundance in eastern Iowa than do the reference material mass fractions, while arsenic, copper, manganese, and vanadium levels are all comparable to the corresponding NIST 2584 values.

The relative abundance of metal species observed in this study is consistent with prior research on indoor PM. Indoor dust ranging 100-250 $\mu \mathrm{m}$ was collected from 48 homes in Ottawa, Ontario, by vacuum cleaner method followed by sieving, and the reported metals included analytes analyzed in eastern Iowa. The median mass fractions of metals in this study (Table S8) agreed with those from Ottawa: Aluminum was the most abundant $\left(22,900 \mathrm{ng} \mathrm{mg}^{-1}\right)$, followed by iron $\left(13,150 \mathrm{ng} \mathrm{mg}^{-1}\right)$, magnesium (9285 $\left.\mathrm{ng} \mathrm{mg}^{-1}\right)$, zinc (633.1 $\left.\mathrm{ng} \mathrm{mg}{ }^{-1}\right)$, manganese $266.5\left(\mathrm{ng} \mathrm{mg}^{-1}\right)$, lead $\left(222.22 \mathrm{ng} \mathrm{mg}^{-1}\right)$, copper $\left(157.30 \mathrm{ng} \mathrm{mg}^{-1}\right)$, nickel $\left(51.5 \mathrm{ng} \mathrm{mg}^{-1}\right)$, vanadium $\left(22.0 \mathrm{ng} \mathrm{mg}^{-1}\right)$, and arsenic (4.1 $\left.\mathrm{ng} \mathrm{mg}^{-1}\right)$ (Rasmussen et al. 2001). Most of the Ottawa mass fractions are within the $95 \%$ confidence interval of the mean in this study (Table S8), although magnesium was more abundant in eastern Iowa $\left(15,000 \mathrm{ng} \mathrm{mg}^{-1}\right)$. In another study, indoor $\mathrm{PM}_{2.5}$ and $\mathrm{PM}_{10}$ samples were collected in Windsor, Ontario, and mass fractions of metals were reported from 121 homes (Rasmussen et al., 2018). While total suspended dust $\left(\mathrm{PM}_{2.5-10}\right)$ reported in Windsor, Ontario, was in good agreement with eastern Iowa ESP results, the Windsor $\mathrm{PM}_{2.5}$ results reported much lower mass fractions of aluminum, magnesium, and iron, suggesting crustal metals are primarily found in settled dust (Rasmussen et al., 2018). Altogether, these results indicate that the ESP collection of TSP in this study agrees with vacuum cleaner $\mathrm{PM}_{10}$ sampling methods in that particle chemistry is dominated by crustal elements.

\section{CONCLUSIONS}

The O-Ion B-1000 ESP is suitable for collecting milligramscale quantities of PM in indoor particulate matter (TSP) for characterization. In our field application, this device collected 6-87 mg of indoor PM over 30 days in 21 homes. As analysis of metals consumed only $0.6-3.5 \mathrm{mg}$ of PM mass, abundant sampling material remained for further characterization studies. In addition to collecting large masses of indoor PM, the ESP operates quietly and is deployable for up to 30 days at a time. Although it produces low quantities of ozone, these levels are not anticipated to be problematic in homes with suitable ventilation. As demonstrated in our characterization studies, the ESP exhibits higher efficiency in collecting particles $>400 \mathrm{~nm}$, particularly those that are conductive, with crustal material and soluble salts being the most efficiently recovered substances from the electrode. Good agreement between our results and prior data on the mass fractions of metals and their relative abundances indicates 
that samples collected with the ESP are comparable in composition to those collected by more traditional methods. Thus, the ESP is an excellent choice for long-term sampling of large masses of indoor PM.

\section{ACKNOWLEDGMENTS}

This work was supported and funded by the University of Iowa Institute for Clinical and Translational Science (ICTS) (Grant number: NIH U54 TR001356) and the Environmental Health Sciences Research Center (EHSRC) (Grant number: NIH P30 ES005605). We thank the Institute for Rural and Environmental Health for use of microbalance facilities, Dr. Peate and the Iowa Trace Element Analysis lab for ICP-MS and clean lab use, and Dr. Latta in Environmental Engineering Services for ICP-MS use.

\section{SUPPLEMENTARY MATERIAL}

Supplementary data associated with this article can be found in the online version at http://www.aaqr.org.

\section{REFERENCES}

Afshar-Mohajer, N., Godfrey, W.H., Rule, A.M., Matsui, E.C., Gordon, J. and Koehler, K. (2017). A low-cost device for bulk sampling of airborne particulate matter: Evaluation of an ionic charging device. Aerosol Air Qual. Res. 17: 1452-1462.

Antonini, J.M., Roberts, J.R., Chapman, R.S., Soukup, J.M., Ghio, A.J. and Sriram, K. (2010). Pulmonary toxicity and extrapulmonary tissue distribution of metals after repeated exposure to different welding fumes. Inhalation Toxicol. 22: 805-816.

Bacchiega, G., Gallimberti, I., Sani, E., Sala, R., Arrondel, V., Hamlil, M. and Christensen, E. (2006). Experimental study of the mass balance in a pilot industrial electrostatic precipitator. J. Electrostat. 64: 297-309.

Bullen, J.J., Rogers, H.J., Spalding, P.B. and Ward, C.G. (2005). Iron and infection: The heart of the matter. FEMS Immunol. Med. Microbiol. 43: 325-330.

Cardello, N., Volckens, J., Tolocka, M.P., Wiener, R. and Buckley, T.J. (2002). Technical note: Performance of a personal electrostatic precipitator particle sampler. Aerosol Sci. Technol. 36: 162-165.

Chow, J.C. and Watson, J.G. (1998). Guideline on speciated particulate monitoring (Draft 3), EPA.

Cortez-Lugo, M., Moreno-Macias, H., Holguin-Molina, F., Chow, J.C., Watson, J.G., Gutierrez-Avedoy, V., Mandujano, F., Hernandez-Avila, M. and Romieu, I. (2008). Relationship between indoor, outdoor, and personal fine particle concentrations for individuals with copd and predictors of indoor-outdoor ratio in Mexico city. $J$. Exposure Sci. Environ. Epidemiol. 18: 109-115.

Cortijo, J., Milara, J., Mata, M., Donet, E., Gavara, N., Peel, S.E., Hall, I.P. and Morcillo, E.J. (2010). Nickel induces intracellular calcium mobilization and pathophysiological responses in human cultured airway epithelial cells. Chem. Biol. Interact. 183: 25-33.
Cox, J., Indugula, R., Vesper, S., Zhu, Z., Jandarov, R. and Reponen, T. (2017). Comparison of indoor air sampling and dust collection methods for fungal exposure assessment using quantitative PCR. Environ. Sci. Processes Impacts 19: 1312-1319.

Curtis, D.B., Meland, B., Aycibin, M., Arnold, N.P., Grassian, V.H., Young, M.A. and Kleiber, P.D. (2008). A laboratory investigation of light scattering from representative components of mineral dust aerosol at a wavelength of $550 \mathrm{~nm}$. J. Geophys. Res. 113: D08210.

Duvall, R.M., Norris, G.A., Dailey, L.A., Burke, J.M., McGee, J.K., Gilmour, M.I., Gordon, T. and Devlin, R.B. (2008). Source apportionment of particulate matter in the U.S. And associations with lung inflammatory markers. Inhalation Toxicol. 20: 671-683.

Figler, B., Sahle, W., Krantz, S. and Ulfvarson, U. (1996). Diesel Exhaust quantification by scanning electron microscope with special emphasis on particulate size distribution. Sci. Total Environ. 193: 77-83.

Fink, D.J. (2017). What Is a safe noise level for the public? Am. J. Public Health 107: 44-45.

Ghio, A.J. (2009). Disruption of iron homeostasis and lung disease. Biochim. Biophys. Acta, Gen. Subj. 1790: 731739.

Hassan, N.M., Rasmussen, P.E., Dabek-Zlotorzynska, E., Celo, V. and Chen, H. (2006). Analysis of environmental samples using microwave-assisted acid digestion and inductively coupled plasma mass spectrometry: maximizing total element recoveries. Water Air Soil Pollut. 178: 323334.

Hewitt, A.D. and Cragin, J.H. (1991). Acid digestion for sediments, sludges, soils, and solid wastes. A proposed alternative to EPA SW 846 Method 3050. Environ. Sci. Technol. 25: 985-986.

Hinds, W. (2004). Aerosol properties. In Aerosols handbook, CRC Press, pp. 18-32.

Hinds, W.C. (1999). Aerosol technology: Properties, behavior, and measurement of airborne particles. Wiley, New York.

Jones, A.P. (1999). Indoor air quality and health. Atmos. Environ. 33: 4535-4564.

Kalogerakis, N., Paschali, D., Lekaditis, V., Pantidou, A., Eleftheriadis, K. and Lazaridis, M. (2005). Indoor air quality - bioaerosol measurements in domestic and office premises. J. Aerosol Sci. 36: 751-761.

Kamens, R., Lee, C.T., Wiener, R. and Leith, D. (1991). A study of characterize indoor particles in three nonsmoking homes. Atmos. Environ. 25: 939-948.

Kim, K.H., Kabir, E. and Kabir, S. (2015). A review on the human health impact of airborne particulate matter. Environ. Int. 74: 136-143.

Lippmann, M. (2012). Health effects of ozone a critical review. JAPCA 39: 672-695.

McGee, J.K., Chen, L.C., Cohen, M.D., Chee, G.R., Prophete, C.M., Haykal-Coates, N., Wasson, S.J., Conner, T.L., Costa, D.L. and Gavett, S.H. (2003). Chemical analysis of world trade center fine particulate matter for use in toxicologic assessment. Environ. Health Perspect. 111: 972-980. 
Mesko, M.F., Hartwig, C.A., Bizzi, C.A., Pereira, J.S.F., Mello, P.A. and Flores, E.M.M. (2011). Sample preparation strategies for bioinorganic analysis by inductively coupled plasma mass spectrometry. Int. J. Mass Spectrom. 307: 123-136.

Miller, A., Frey, G., King, G. and Sunderman, C. (2010). A handheld electrostatic precipitator for sampling airborne particles and nanoparticles. Aerosol Sci. Technol. 44: 417-427.

Mizuno, A. (2000). Electrostatic precipitation. IEEE Trans. Dielectr. Electr. Insul. 7: 615-624.

Nazaroff, W.W. (2018). The particles around US. Indoor Air 28: $215-217$.

NEMI (2018). 3125 Metals by inductively coupled plasma mass spectrometry. In Standard methods for the examination of water and wastewater, American Public Health Association.

Qi, L. and Yuan, Y. (2011). Characteristics and the behavior in electrostatic precipitators of high-alumina coal fly ash from the Jungar power plant, Inner Mongolia, China. $J$. Hazard. Mater. 192: 222-225.

Rasmussen, P.E., Subramanian, K.S. and Jessiman, B.J. (2001). A multi-element profile of house dust in relation to exterior dust and soils in the city of Ottawa, Canada. Sci. Total Environ. 267: 125-140.

Rasmussen, P.E., Levesque, C., Chénier, M. and Gardner, H.D. (2018). Contribution of metals in resuspended dust to indoor and personal inhalation exposures: Relationships between $\mathrm{PM}_{10}$ and settled dust. Build. Environ. 143: 513 522.
Sandu, I., Chirazi, M., Canache, M., Sandu, I.G., Alexianu, M.T., Sandu, A.V. and Vasilache, V. (2010). Research on $\mathrm{NaCl}$ saline aerosols I. Natural and artificial sources and their implications. Environ. Eng. Manage. J. 9: 881-888.

See, S.W. and Balasubramanian, R. (2008). Chemical characteristics of fine particles emitted from different gas cooking methods. Atmos. Environ. 42: 8852-8862.

U.S. EPA (U.S. Environmental Protection Agency) (1982). Review of the national ambient air quality standards for particulate matter: Policy assessment of scientific and technical information. OAQPS Staff Paper. EPA-452/R96-013. U.S. Environmental Protection Agency, Office of Air Quality Planning and Standards, Research Triangle Park, N.C.

Wallace, L. (2012). Indoor particles: A review. J. Air Waste Manage. Assoc. 46: 98-126.

Yanosky, J.D., Williams, P.L. and MacIntosh, D.L. (2002). A comparison of two direct-reading aerosol monitors with the federal reference method for $\mathrm{PM}_{2.5}$ in indoor air. Atmos. Environ. 36: 107-113.

Zhao, W., Hopke, P.K., Norris, G., Williams, R. and Paatero, P. (2006). Source apportionment and analysis on ambient and personal exposure samples with a combined receptor model and an adaptive blank estimation strategy. Atmos. Environ. 40: 3788-3801.

Received for review, April 3, 2019

Revised, August 28, 2019

Accepted, September 13, 2019 